\title{
Peroral endoscopic myotomy in a case of recurrent epiphrenic diverticulum after surgery
}

Epiphrenic diverticula are pulsion-type diverticula most commonly located in the distal esophagus. They are classed as "pseudo-diverticula" and are usually associated with esophageal motility disorders (EMD) [1].

The main symptoms leading to referral include dysphagia, regurgitation, and chest pain [2]. In symptomatic patients, laparoscopic or thoracoscopic diverticulotomy combined with a distal esophagogastric myotomy is considered the "gold standard" treatment. Peroral endoscopic myotomy (POEM), previously introduced to treat achalasia, is increasingly used to treat other types of EMD and to perform diverticulotomy (D-POEM) [3].

We describe the case of an 86-year-old man with recurrent symptoms after failure of laparoscopic diverticulotomy and Heller myotomy. High-resolution manometry and barium swallow revealed a recurrent epiphrenic diverticulum with primary EMD. Salvage POEM and D-POEM were performed under general anesthe-

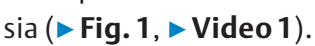

Endoflip (Medtronic, Minneapolis, Minnesota, USA) was used intraoperatively to document compliance and distensibility changes at the gastroesophageal junction (GEJ) and at the diverticulum in order to precisely guide myotomy and septotomy. After submucosal injection and mucosal incision, performed on the opposite wall and $4 \mathrm{~cm}$ proximally to the diverticulum, a longitudinal submucosal tunnel was created using a Triangle Tip knife (Olympus, Tokyo, Japan) and carried to $2 \mathrm{~cm}$ below the GEJ. A proximal-to-distal myotomy was subsequently performed with preservation of the longitudinal muscles. Complete septotomy of the diverticulum was then performed. Endoflip measurements were repeated to ensure the completeness of the myotomy. Finally, the mucosal incision was closed with endoclips.

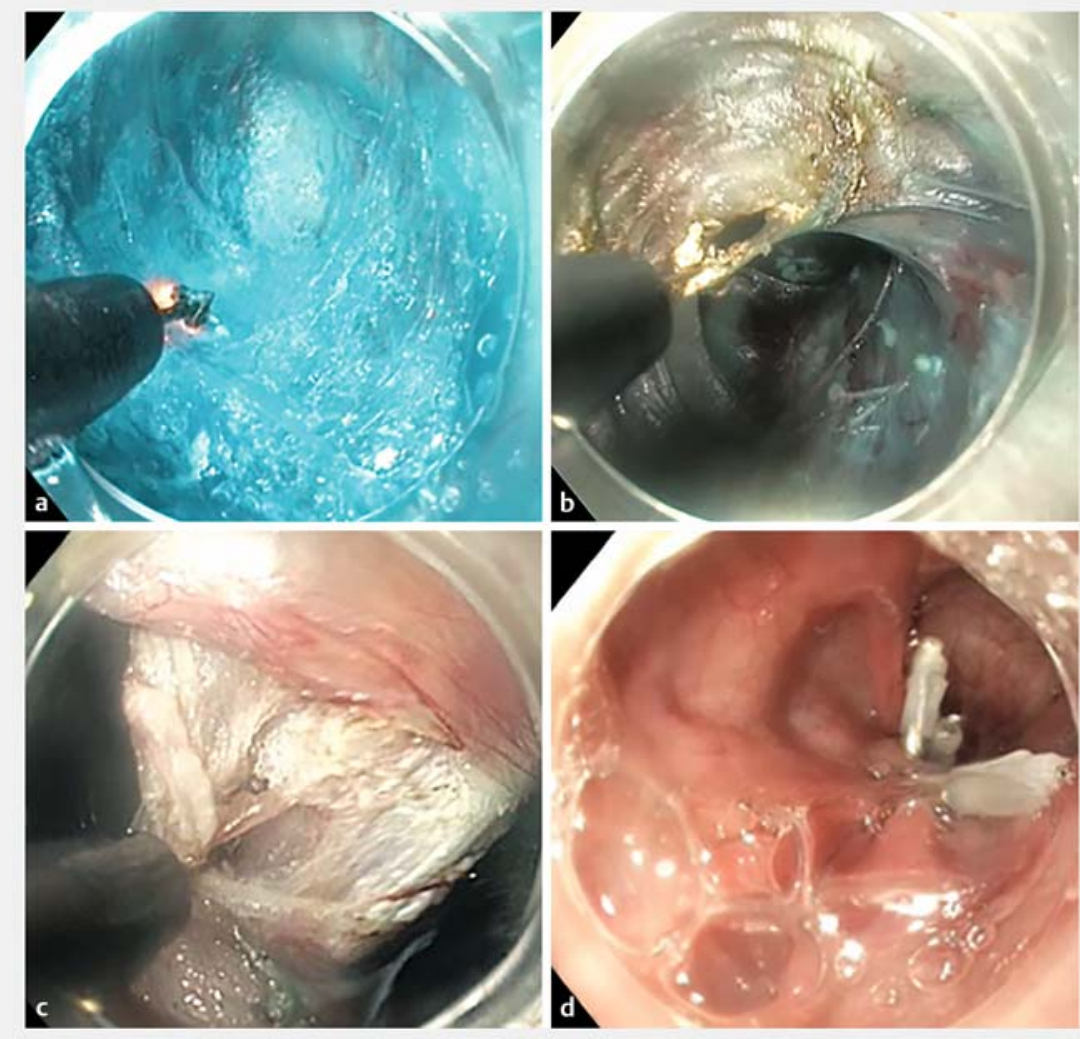

- Fig. 1 Salvage peroral endoscopic myotomy (POEM) associated with diverticulotomy (D-POEM) for the management of a recurrent epiphrenic diverticulum after surgery. a Submucosal tunneling. b Myotomy. c Septotomy. $\mathbf{d}$ Closure of the mucosal incision with endoclips.

The postoperative course was uneventful. Esophageal emptying was satisfactory on barium swallow performed on postoperative Day 1 and a soft diet was started. At the 2-month follow-up visit, the patient had regained $5 \mathrm{~kg}$ in weight and had complete remission of symptoms.

POEM combined with a D-POEM procedure may be safe and effective in the treatment of recurrent epiphrenic diverticula after surgery.

Endoscopy_UCTN_Code_TTT_1AO_2AN

\section{Competing interests}

Jacques Marescaux is the President of IRCAD, which is partly funded by Karl Storz, Siemens, and Medtronic. Lee Swanström consults for Medtronic, Boston Scientific, and Olympus. Margherita Pizzicannella, Silvana Perretta, Andrea Spota and Bernard Dallemagne have no conflict of interest to declare. 


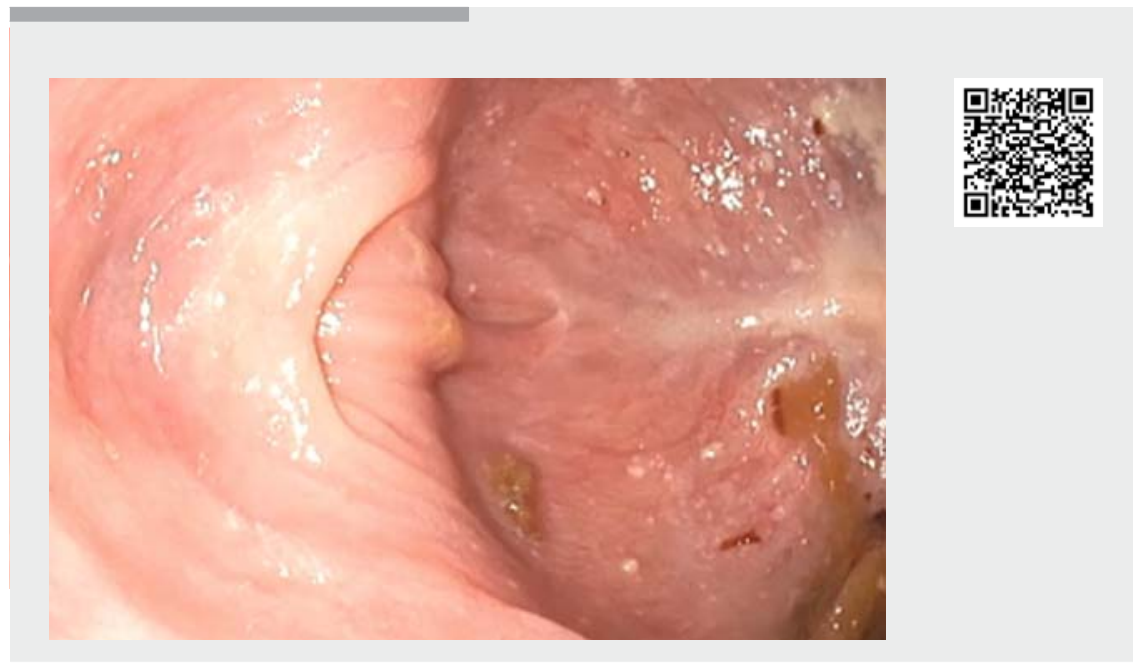

Video 1 A combined procedure of peroral endoscopic myotomy (POEM) associated with diverticulotomy (D-POEM) to treat a recurrent epiphrenic diverticulum with an associated esophageal motility disorder after surgery. Endoflip was used to evaluate distensibility changes before and after the procedure. Source for graphical illustration: Catherine Cers, IRCAD, Strasbourg.

The authors

Margherita Pizzicannella ${ }^{1}$, Andrea Spota ${ }^{2}$, Bernard Dallemagne ${ }^{3}$, Lee Swanström', Jacques Marescaux ${ }^{3}$, Silvana Perretta ${ }^{1,3,4}$

1 IHU-Strasbourg, Institute of Image-Guided Surgery, Strasbourg, France

2 Università degli studi di Milano, scuola di specializzazione in Chirurgia Generale, Milano, Italy

3 IRCAD, Research Institute Against Digestive Cancer, Strasbourg, France

4 Department of Digestive and Endocrine Surgery, Nouvel Hôpital Civil, Strasbourg University Hospital, Strasbourg, France

\section{Corresponding author}

\section{Margherita Pizzicannella, MD}

IHU-Strasbourg, Institute of Image-Guided Surgery, 1 place de l'Hôpital, 67000,

Strasbourg, France

marghe.pizzicannella@gmail.com

\section{References}

[1] Kinoshita M, Tanaka S, Kawara F et al. Peroral endoscopic myotomy alone is effective for esophageal motility disorders and esophageal epiphrenic diverticulum: a retrospec- tive single-center study. Surg Endosc 2020. doi:10.1007/s00464-019-07340-6

[2] Soares R, Herbella FA, Prachand VN et al. Epiphrenic diverticulum of the esophagus. From pathophysiology to treatment. J Gastrointest Surg 2010; 14: 2009-2015

[3] Yang J, Zeng X, Yuan X et al. An internationa study on the use of peroral endoscopic myotomy (POEM) in the management of esophageal diverticula: the first multicenter D-POEM experience. Endoscopy 2019; 51: 346-349

Bibliography

Endoscopy 2021; 53: E92-E93

DOI 10.1055/a-1201-2725

ISSN 0013-726X

published online 13.7.2020

(c) 2020. Thieme. All rights reserved.

Georg Thieme Verlag KG, Rüdigerstraße 14,

70469 Stuttgart, Germany

\section{ENDOSCOPY E-VIDEOS}

https:/|eref.thieme.de/e-videos

回回 Endoscopy E-Videos is a free access online section, reporting 回: on interesting cases and new techniques in gastroenterological endoscopy. All papers include a high quality video and all contributions are freely accessible online.

This section has its own submission website at https://mc.manuscriptcentral.com/e-videos 